\title{
Clinical outcomes and survivorship of two-stage total hip or knee arthroplasty in septic arthritis: a retrospective analysis with a minimum five-year follow-up
}

\author{
Antonio Russo $^{1,2}$ (D) Luca Cavagnaro ${ }^{3} \cdot$ Francesco Chiarlone $^{3} \cdot$ Antonio Clemente $^{4} \cdot$ Sergio Romagnoli $^{5}$. \\ Giorgio Burastero ${ }^{5}$
}

Received: 22 January 2021 / Accepted: 17 March 2021 / Published online: 27 March 2021

(C) The Author(s) 2021

\begin{abstract}
Purpose Septic arthritis of the native joint is challenging for orthopedic surgeons because it may lead to wide bone defects and severe impairment of joint function. This study aimed to analyze clinical functional outcomes, the rate of infection eradication, and survival of implants of patients who underwent two-stage arthroplasty for septic arthritis of the hip and knee.

Methods A retrospective single-centre analysis was conducted of patients treated for septic arthritis of the hip and knee joints through a two-stage surgery between 2012 and 2015. Clinical and radiological records were gathered from the prospectively collected Institutional Arthroplasty Registry. Patients' pre-operative Harris hip scores and Knee Society scores were compared with those obtained at the latest follow-up. Kaplan-Meier curves were generated to assess survival of implants.

Results Forty-seven patients were included. The mean follow-up was $85.2 \pm 15.4$ months. The Harris hip score improved from $39.4 \pm 9.9$ to $84.5 \pm 10.8$ points $(p<0.001)$. The Knee Society score improved from $40.7 \pm 8.4$ to $86.0 \pm 7.8$ points $(p<0.001)$. Knee Society score-function increased from $25.7 \pm 14.2$ to $85.4 \pm 23.4$ points $(p<0.001)$. The infection eradication rates were $92.0 \%$ and $90.9 \%$ in patients who underwent hip and knee operation, respectively $(p=0.891)$. Overall survivorship of implants after the second stage was $93.6 \%$.

Conclusions Two-stage arthroplasty provides good to excellent clinical outcomes in cases of active septic arthritis of the hip and the knee, high rates of infection control, and implant survival.
\end{abstract}

Keywords Septic arthritis · Two-stage arthroplasty $\cdot$ Cement spacer · Total hip arthroplasty · Total knee arthroplasty

Antonio Russo

russo.antonio.92@gmail.com

1 Orthopaedic Clinic, Ospedale Policlinico San Martino, Largo R. Benzi 10, 16132 Genova, Italy

2 Department of Surgical Sciences and Integrated Diagnostic (DISC), University of Genoa, Viale Benedetto XV 6, 16132 Genoa, Italy

3 Joint Arthroplasty Unit, Orthopaedic and Traumatology 2, Santa Corona Hospital, Viale 25 Aprile 38, 17027 Pietra Ligure, Italy

4 Department of Orthopedics and Traumatology, CTO Hospital, University of Turin, Via G. Zuretti 29, 10126 Turin, Italy

5 Prosthetic Surgery Centre, IRCCS Istituto Ortopedico Galeazzi, Via Riccardo Galeazzi 4, 20161 Milan, Italy

\section{Introduction}

Septic arthritis (SA) is a rare but potentially devastating condition, causing significant pain and disability to affected patients [1, 2]. Its management is challenging, and a multidisciplinary approach is always required. Recently, the incidence of SA has increased because of the aging of the population and the numerous intra-articular procedures performed. Generally, the extent of infection in the setting of SA is limited compared with periprosthetic joint infection (PJI) because of the absence of previously implanted devices. However, since early onset SA can be treated with open arthroscopic debridement, whereas chronic infections need more radical resection and debridement and are associated with wider joint degeneration, the timing of the diagnosis is fundamental [3]. Over the years, several surgical strategies have been proposed to treat evolutive SA. In 1943, Girdlestone described resection arthroplasty, which was demonstrated to efficiently relieve 
pain and morbidity related to infection; however, leg length discrepancies and poor functional outcomes were common complications of the procedure $[4,5]$. More recently, total joint arthroplasty (TJA) has been described as a reliable solution to treat SA with wide joint degeneration to control symptoms and guarantee acceptable restoration of function [6-9]. One-stage TJA has demonstrated good functional outcomes, but the results are still unsatisfactory in terms of eradication in cases of active infection $[7,10,11]$.

The use of cement spacers in staged procedures is well established, showing excellent outcomes in joint function and infection eradication [12-15].

The aim of this study was to assess the clinical outcomes of patients treated with two-stage TJA in the setting of SA of the hip and knee at the medium-term follow-up. Endpoints of this analysis were clinical and functional outcomes, expressed as clinical scores of validated questionnaires, rate of eradication of the infection, and survivorship of the implants in this cohort of patients.

\section{Materials and methods}

The local institutional review board approved this singlecenter study. Informed consent was obtained from all individual participants included in the study.

\section{Data collection and inclusion criteria}

A retrospective analysis of our prospectively collected Institutional Arthroplasty Registry was conducted from January 1st, 2012 to January 1st, 2015, searching for patients treated for SA. Patients suffering from SA of the hip or the knee joint treated with two-stage TJR with at least five years of follow-up and who gave their written informed consent were considered eligible for the study. Patients with primary SA, SA following previous surgery, and post-infiltrative SA were all included in the analysis. Patients who suffered from PJI, had incomplete clinical data, or were missing at follow-up were excluded. Smoking status, age at time of surgery, and comorbidities were not considered exclusion criteria for the study.

The diagnosis of SA was made based on one or a combination of the following parameters: clinical signs of infection (oedema, erythema, functional limitation, a draining sinus communicating with the joint), elevated serum C-reactive protein ([CRP] $>5 \mathrm{mg} /$ $\mathrm{dL})$ and erythrocyte sedimentation rate ([ESR] $>30 \mathrm{~mm} / \mathrm{h}$ ) values, radiographic findings of bone resorption and loss of articular space, finding of intra-operative purulence, and positive intra-operative or synovial fluid microbiology. General characteristics of the study populations, such as age, sex, body mass index (BMI), American Society of Anesthesiologists (ASA) score, follow-up, interval between the two stages, and pathogens involved were retrieved and are presented in Tables 1 and 2.

\section{Clinical and radiographic assessment}

The clinical and radiographic assessments of patients were conducted pre-operatively and after the second stage at one, three and six months. Then, patients were evaluated once per year. Clinical evaluation of patients treated for SA of the hip included Harris hip score (HHS) [16] evaluation and physical examination. Radiographic assessment included an anteroposterior (AP) view of the pelvis and AP and lateral views of the hip. Similarly, patients who suffered SA of the knee underwent physical examination, Knee Society score (KSS) [17] evaluation, KSS for function (KSS-F), and anteroposterior and lateral radiographs of the knee (Table 3). Radiographic images were assessed by two orthopedic fellows (A.R., A.C.) preoperatively and at final follow-up; these assessments aimed to identify loosening, radiolucent lines, malposition, component migration, leg length discrepancy (LLD), hip stem subsidence, and heterotopic ossifications. The Brooker classification was used to classify hip heterotopic ossification [18]. Radiological evaluation of the knees was carried out according to the Knee Society total knee arthroplasty radiographic evaluation for long-stemmed revision prostheses to fully evaluate the entire lengths of the prostheses [19]. Disagreements were resolved via discussion among all the authors.

\section{Surgical procedures}

All the two-stage procedures were performed by a single surgeon experienced in complex septic TJA surgery (G.B.). All the hips were approached through a posterolateral incision, whereas all the knees were operated on using a medial parapatellar approach. During the first-stage surgery, a femoral head and acetabulum or knee resection was performed, along with extensive debridement of the surrounding tissues involved in the infectious process. Three to six samples of septic tissue were withdrawn for cultures. Subsequently, joints were irrigated with $10 \mathrm{~L}$ of an antiseptic solution, and a preformed articulating antibiotic-loaded cement spacer containing gentamicin and vancomycin was positioned. The degree of bone defect was defined by the senior author at the time of surgery using the Paprosky [20, 21] and the Anderson Orthopedic Research Institute (AORI) [22] classifications (Table 4). At least two weeks of intravenous antibiotic therapy was administered. Then, the switch to oral antibiotic therapy or targeted intravenous antibiotic therapy for a period of at least four weeks was decided on based on the microbiological results.

During the second stage, the spacer was removed, and a further debridement was performed. Three to six samples were retrieved for microbiological analysis, as was a specimen for frozen section histology. In case of persistence of infection, a spacer exchange was performed. Depending on the case, the senior surgeon decided how to manage each bone defect and which type of prosthetic design to implant. 
Table 1 Demographic characteristics of patients included in the study

\begin{tabular}{|c|c|c|c|}
\hline & & Hips $n=25(\%)$ & Knees $n=22(\%)$ \\
\hline \multirow[t]{2}{*}{ Sex } & M & $13(52)$ & $12(54.5 \%)$ \\
\hline & $\mathrm{F}$ & $12(48)$ & $10(45.5 \%)$ \\
\hline \multicolumn{2}{|l|}{ Mean age $( \pm \mathrm{SD}), \mathrm{y}$} & $56.4( \pm 15.0)$ & $55.3( \pm 13.9)$ \\
\hline \multicolumn{2}{|c|}{ Mean BMI $( \pm \mathrm{SD}), \mathrm{kg} / \mathrm{m}^{2}$} & $25.7( \pm 4.6)$ & $27.2( \pm 4.1)$ \\
\hline \multirow[t]{3}{*}{ ASA } & I & $10(40)$ & $11(50)$ \\
\hline & II & $7(28)$ & $6(27.3)$ \\
\hline & III & $8(32)$ & $5(22.7)$ \\
\hline \multirow[t]{2}{*}{ Side } & $\mathrm{L}$ & $19(76)$ & $16(72.7)$ \\
\hline & $\mathrm{R}$ & $6(24)$ & $6(27.3)$ \\
\hline \multirow[t]{3}{*}{ Aetiology } & Post-surgery & $4(16)$ & $13(59.1)$ \\
\hline & Post-infiltrative & $2(8)$ & $4(18.2)$ \\
\hline & Primary & $19(76)$ & $6(27.3)$ \\
\hline \multirow[t]{8}{*}{ Main comorbidities } & $\mathrm{DM}$ & $7(28)$ & $5(22.7)$ \\
\hline & Drug abuse & $6(24)$ & $4(18.2)$ \\
\hline & HIV & $5(25)$ & $3(13.6)$ \\
\hline & $\mathrm{HCV}$ & $4(16)$ & $4(18.2)$ \\
\hline & Systemic TBC & $1(4)$ & - \\
\hline & CVD & $8(32)$ & $6(27.3)$ \\
\hline & CPD & $4(16)$ & $5(22.7)$ \\
\hline & Epilepsy & $2(8)$ & $1(4.5)$ \\
\hline \multicolumn{2}{|c|}{ Mean interstage interval $( \pm \mathrm{SD}), \mathrm{w}$} & $14.5 \pm 2.9$ & $14.9 \pm 2.8$ \\
\hline \multicolumn{2}{|c|}{ Mean follow-up ( \pm SD), $m$} & $86.7 \pm 16.0$ & $85.6 \pm 15.1$ \\
\hline
\end{tabular}

$A S A$, American Society of Anesthesiology; $C P D$, chronic pulmonary disease; $C V D$, cardiovascular disease; $D M$, diabetes mellitus; $F$, female; $H C V$, hepatitis $\mathrm{C}$ virus; $H I V$, human immunodeficiency virus; $L$, left; $M$, male; $m$, months; $n$, numbers; $R$, right; $S D$, standard deviation; $T B C$, tuberculosis; $y$, years

\section{Post-operative pathway}

A specific antibiotic therapy was prescribed until the results of the intra-operative microbiology were received and continued thereafter when needed. On the second post-operative day the

Table 2 Pathogens identified in preoperative microbiological analysis of synovial fluid

\begin{tabular}{lll}
\hline & Hips, $n(\%)$ & Knees, $n(\%)$ \\
\hline MSSA & $7(28)$ & $6(27.3)$ \\
MRSA & $3(12)$ & $1(4.5)$ \\
CoN staphylococci & - & $3(13.6)$ \\
Streptococcus sp. & $1(4)$ & $2(9.1)$ \\
Pseudomonas sp. & $2(8)$ & $1(4.5)$ \\
Mycobacterium sp. & $2(8)$ & $2(9.1)$ \\
E. coli & $1(4)$ & - \\
Proteus sp. & $1(4)$ & - \\
Polymicrobial & $2(8)$ & $2(4.5)$ \\
Culture negative & $6(24)$ & $5(22.7)$ \\
\hline
\end{tabular}

MRSA, methicillin-resistant Staphylococcus aureus; MSSA, methicillinsensible Staphylococcus aureus; CoN, coagulase-negative; sp., species surgical drain was removed, and patients were encouraged to engage in partial weight-bearing with a walker or crutches. Thromboembolism prophylaxis was started on the same day as the surgery with heparins and compressive stockings, and it was continued for at least 45 days. Celecoxib $200 \mathrm{mg}$ twice daily was administered to patient who had no contraindications for 20 days post-operatively for the prevention of heterotopic ossifications.

\section{Statistical analysis}

Statistical analysis was conducted using IBM SPSS Statistics version 26.0 (IBM Corp., Armonk, NY, USA). Categorical variables were expressed as the number of events or percentages. Continuous variables were expressed as the mean \pm standard deviation (SD). Pre-operative clinical score values and at final follow-up were compared using the paired $t$-test. Kaplan-Meier survival curves were provided to analyze the success rate of treatments. Treatment success was defined as infection eradication, absence of major complications during the interstage period that required spacer exchange or conversion to TJA, or any additional surgery. Statistical significance was set at $p<0.05$ for all the analyzed variables. 
Table 3 Clinical functional outcomes

\begin{tabular}{lll}
\hline & Hips $(n=25)$ & $p$-value \\
Mean HHS $( \pm \mathrm{SD})$ & $39.4 \pm 9.9$ & $<0.001$ \\
Pre-operative & $84.5 \pm 10.8$ & \\
Final & & \\
Mean offset $( \pm \mathrm{SD})$ & $51.1 \pm 5.0$ & 0.31 \\
Pre-operative & $52.0 \pm 4.6$ & \\
Final & $7.4 \pm 7.0$ & \\
Post-operative LLD & Knees $(n=22)$ & $<0.001$ \\
& & \\
Mean KSS $( \pm \mathrm{SD})$ & $40.7 \pm 8.4$ & $<0.001$ \\
Pre-operative & $86.0 \pm 7.8$ & \\
Final & & \\
Mean KSS-F $( \pm \mathrm{SD})$ & $25.7 \pm 14.2$ & \\
Pre-operative & $85.4 \pm 23.4$ & \\
Final &
\end{tabular}

$H H S$, Harris hip score; KSS, Knee Society score; KSS-F, Knee Society score-function; $L L D$, leg length discrepancy; $S D$, standard deviation

$p$-value is relative to the comparison of preoperative values and those obtained at latest follow-up

\section{Results}

Forty-seven consecutive patients ( 25 male, 22 female) met the inclusion criteria and were enrolled in the study. Of these, 25 (53.2\%) suffered from SA of the hip and $22(46.8 \%)$ had SA of the knee. The overall mean age at stage one was $55.9 \pm 14.3$ years. The overall mean BMI was $26.4 \pm 4.4 \mathrm{~kg} / \mathrm{m}^{2}$. All the patients had been reimplanted at a mean of 14.7 (range, 10.7 to 22.9 ) weeks after the first stage. The mean follow-up was 85.2 \pm 15.4 months. The most common comorbidities were chronic cardiovascular diseases $(29.8 \%)$ and diabetes mellitus (25.5\%). A history of intravenous drug abuse (21.3\%), HIV (17.7\%), and HCV (17.0\%) were other frequently encountered conditions in this series. Seventeen $(36.2 \%)$ patients had previous surgery to the affected joint and $6(12.8 \%)$ had previous infiltrative therapies; in $24(51.1 \%)$ cases, the infection was classified as primary SA. Details on demographics, ASA scores, comorbidities, and general characteristics of the study population are presented in Table 1 .

\section{Pathogens}

Methicillin-sensible Staphylococcus aureus (MSSA) was the most common pathogen found at microbiology (13 cases, 27.7\%). Methicillin-resistant Staphylococcus aureus (MRSA) was identified in four cases ( $8.5 \%$ ), as were coagulase-negative staphylococci (CoN-St) and Mycobacterium tuberculosis. Polymicrobial and culture-negative infections were encountered in $4(8.5 \%)$ and $11(23.4 \%)$ cases, respectively. The complete list of pathogens identified preoperatively is shown in Table 2.
Table 4 Classification of bone defects

\begin{tabular}{lll}
\hline & & Hips $n=25(\%)$ \\
Paprosky acetabulum & I & $7(28.0)$ \\
& IIA & $6(24.0)$ \\
& IIB & $5(20.0)$ \\
& IIIA & $6(24.0)$ \\
Paprosky femur & IIIB & $1(4.0)$ \\
I & $20(80.0)$ \\
AORI femur & II & $5(20.0)$ \\
& & Knees $n=22(\%)$ \\
AORI tibia & I & $9(40.9)$ \\
& IIA & $4(18.2)$ \\
& IIB & $5(22.7)$ \\
& III & $4(18.2)$ \\
& I & $8(36.4)$ \\
& IIA & $5(22.7)$ \\
& IIB & $4(18.2)$ \\
& III & $5(22.7)$ \\
\hline
\end{tabular}

AORI, Anderson Orthopedic Research Institute

\section{Clinical and functional outcomes}

The mean HHS significantly improved from $39.4 \pm 9.9$ points pre-operatively to $84.5 \pm 10.8$ points at final follow-up $(p<$ $0.001)$. Differences between offset on the healthy contralateral side $(51.1 \pm 5.0 \mathrm{~mm})$ and on the operated side at final followup $(52.0 \pm 4.6 \mathrm{~mm})$ were not considered statistically significant $(p=0.31)$. The mean LLD was $7.4 \pm 7.0 \mathrm{~mm}$.

The mean KSS improved from $40.7 \pm 8.4$ points preoperatively to $86.0 \pm 7.8$ points at final follow-up ( $p<$ $0.001)$. The mean KSS-F improved from $25.7 \pm 14.2$ points to $85.4 \pm 23.4$ points $(p<0.001)$.

\section{Complications}

The overall complication rate was $27.7 \%$. Major complications that required revision or reoperation were reported in $14.9 \%$ of cases.

In two cases (4.3\%), patients underwent spacer exchange for persistency of infection. Of these, one patient was diagnosed with primary Mycobacterium tuberculosis SA of the hip and the other had a polymicrobial infection of the knee.

Two patients $(4.3 \%)$ underwent hip spacer dislocation, which was managed through revision TJA with good results. One patient $(2.1 \%)$ had positive intra-operative microbiology at the time of the second stage and underwent suppressive antibiotic therapy with good results.

One case of aseptic loosening that required revision $(2.1 \%)$ of the knee after final implantation was registered. One patient (2.1\%) had infection recurrence in the hip after the second 
Fig. 1 Survival curve of twostage procedures free from septic recurrences. $\mathrm{H}$, hips; $\mathrm{K}$, knees; $\mathrm{m}$, months

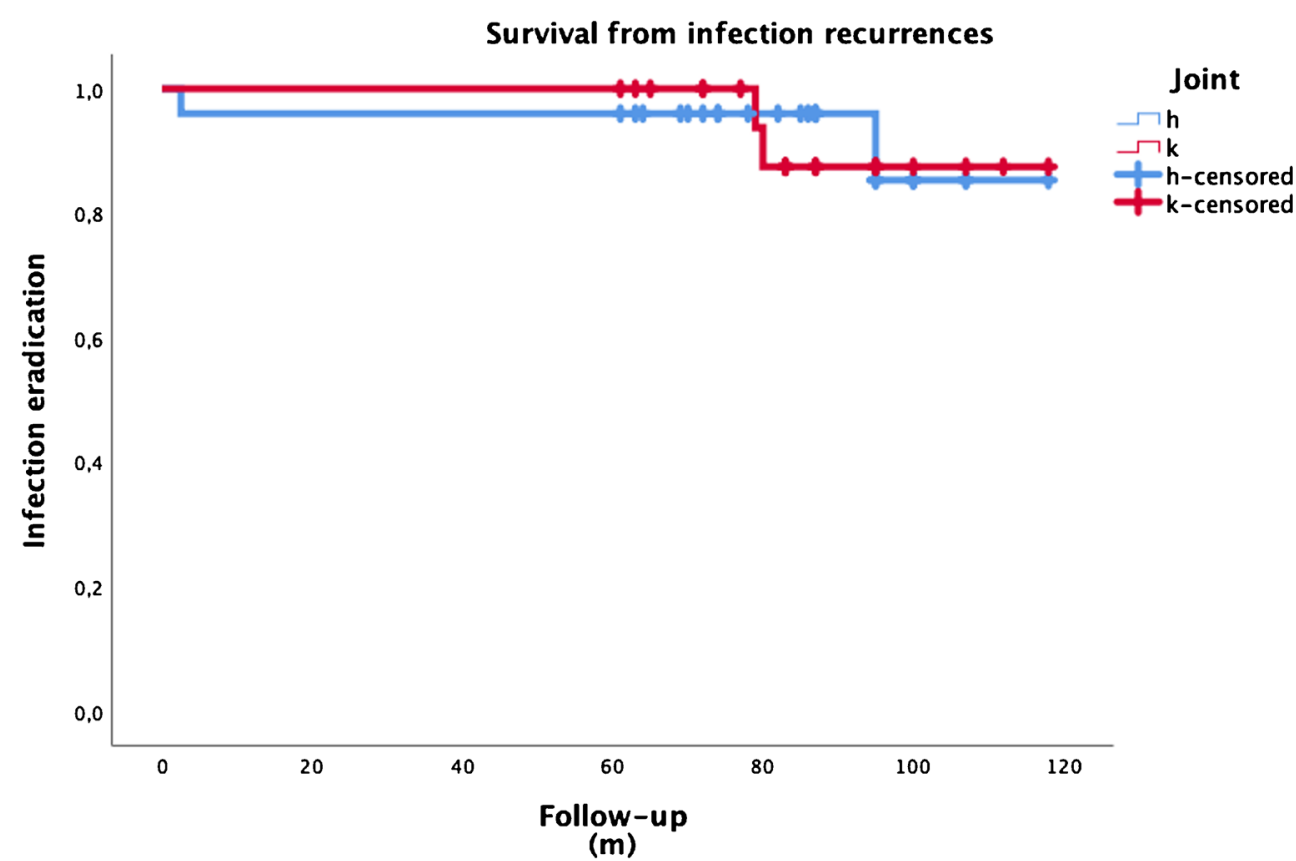

stage, which required prosthesis removal and a Girdlestone procedure.

Five (10.6\%) patients developed heterotopic ossification of the hip, visible on radiographs. However, the ossifications were non-progressive, the patients remained asymptomatic, and no further treatment was needed.

One patient $(2.1 \%)$ with prior internal fixation of the femur with a plate suffered from extensive damage to the knee extensor mechanism, which required reconstruction through the medial gastrocnemius flap during the second stage. One patient $(2.1 \%)$ who underwent hip operation developed haematoma after spacer implantation, which required surgical drainage.

One patient $(2.1 \%)$ who underwent hip surgery suffered from a previous multifocal diaphyseal fracture of the femur with subsequent neurapraxia of the sciatic nerve and had poor HHS at final follow-up (48 points). No complications related to the SA and its treatment were responsible for the poor score.
Fig. 2 Survival curve of implants free from septic and mechanical complications. H, hips; K, knees; $\mathrm{m}$, months; TJA, total joint arthroplasty

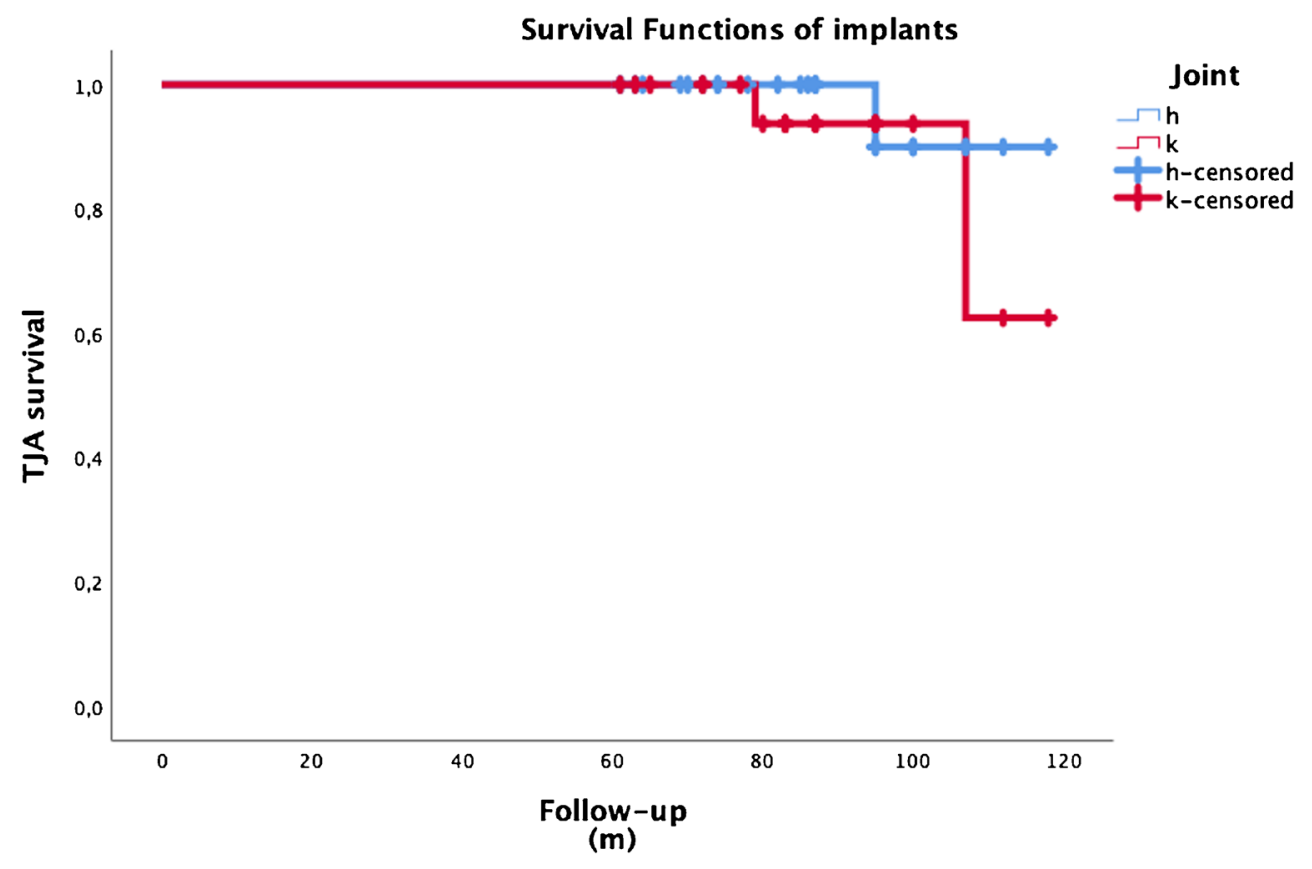


Fig. 3 Images of a 76-year-old female patient suffering from polymicrobial SA of the right hip. a AP view of the pelvis showing Paprosky type IIIB acetabular bone defect and Paprosky type I bone defect on the femur. b AP radiograph of the pelvis 2 months after articulating cement spacer implantation. On the femur, a prefabricated cement spacer was used, whereas a hand-molded acetabular spacer was used on the acetabular side. c, $\mathbf{d}$ AP and axial CT details of acetabular bone defect. e, $\mathbf{f} A \mathrm{P}$ and lateral views of the right hip at final follow-up. A single wedge cementless stem was used, and the extensive acetabular defect was managed through a custom-made component
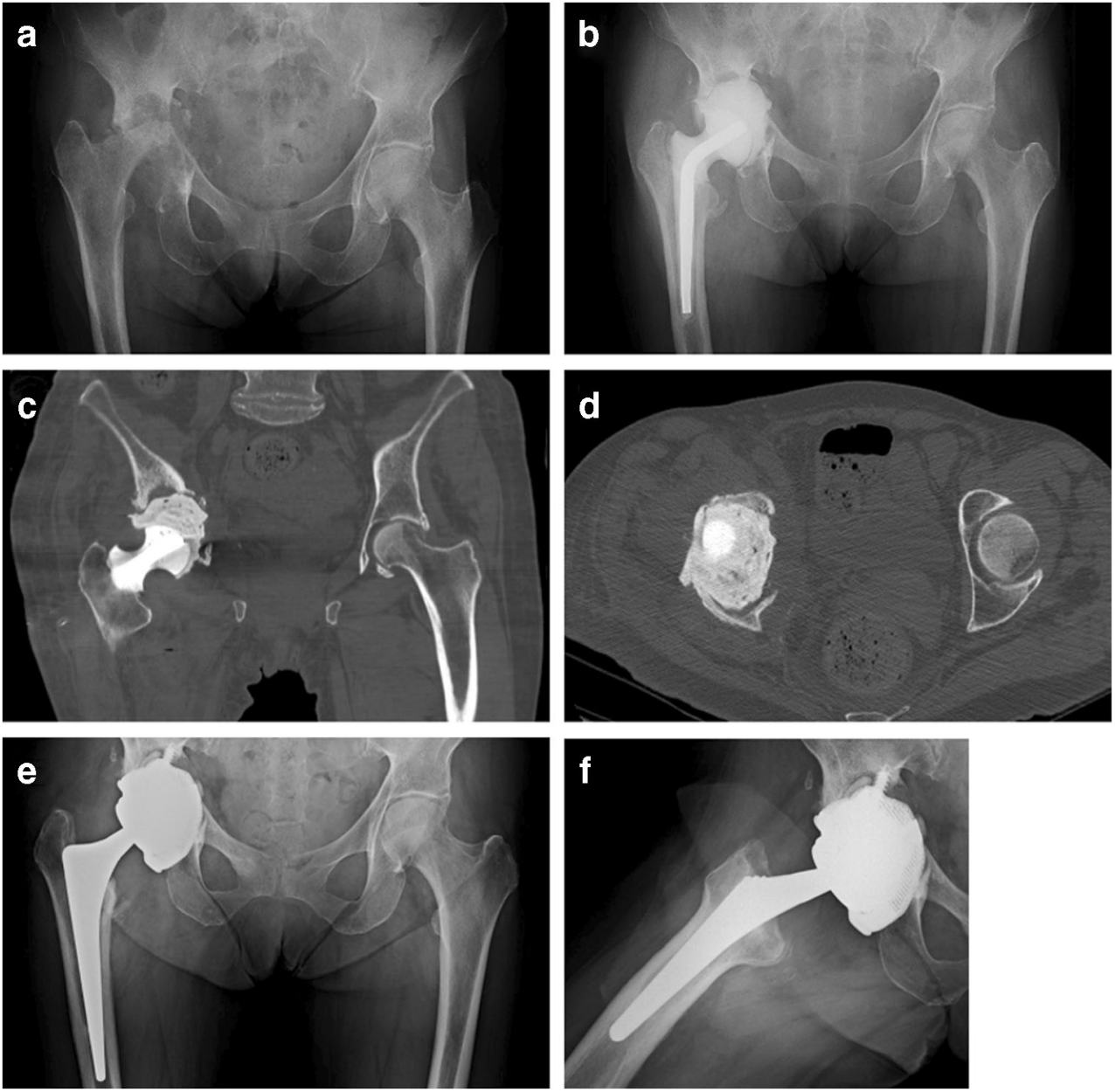

\section{Eradication rate and survival analysis}

Eradication of the infection was defined as the absence of any infection recurrence after spacer implantation or second-stage surgery. The overall eradication rate was $91.5 \%$. Eradication rate was $92.0 \%$ in patients who underwent hip surgery and $90.9 \%$ in patients who underwent knee operation. This difference was not statistically significant $(p=0.891)$. Figure 1 displays the survival curve for septic complications.

Overall survivorship of implants after the second stage was 93.6\%. The survivorships of hip and knee implants were $96.0 \%$ and $90.9 \%$, respectively. The difference observed in terms of implant survival rate between hip and knee prosthesis was not considered statistically significant ( $p=0.447)$. The survival curves of prosthetic implants after the second stage are presented in Fig. 2.

\section{Discussion}

The appropriate surgical approach to evolutive SA associated with extensive joint degeneration continues to be debated.
One-stage replacement was proposed as a viable technique to manage patients with SA of the hip and knee, but the risk of increased PJI is still concerning [7, 11]. Moreover, onestage procedures are not indicated in cases of active infection. In these cases, two-stage replacement may be considered the treatment of choice to recover function and avoid infection recurrences [14, 23]. Papanna et al. [10] applied a differentiated protocol based on active versus quiescent SA, which was treated using two-stage versus one-stage replacement, respectively. In this cohort of 18 patients, no recurrence of infection or implant failures were registered at a mean 70-month followup. Anagnostakos et al. [24] treated 16 patients with two-stage replacement, achieving $88 \%$ control of infection. In general, the available literature demonstrated that two-stage procedures after SA provided good to excellent clinical results, with success rates ranging from 84 to $100 \%[6,12,15,25,26]$. The results of this study demonstrated overall primary infection control in $92 \%$ of hips and $90.9 \%$ of knees and an overall implant survival of $93.6 \%$ after the second stage. Notably, patients developing SA are often affected by specific comorbidities (diabetes mellitus, intravenous drug abuse) that are well-known risk factors for PJI and generalized sepsis. From 
Fig. 4 Images of a 64-year-old male patient suffering from a tubercular SA of the left knee. a, $\mathbf{b}$ $\mathrm{AP}$ and lateral view of the left knee demonstrating the wide degenerative process and deformity resulting from the infection. $\mathbf{c}, \mathbf{d}$ $\mathrm{AP}$ and lateral view of the knee 3 months after the prefabricated articulating cement spacer was positioned showing a wide cavitary bone defect on the medial femoral condyle. e, f AP and lateral radiographs at final follow-up. The medial femoral condyle was reconstructed using a tantalum acetabular augment
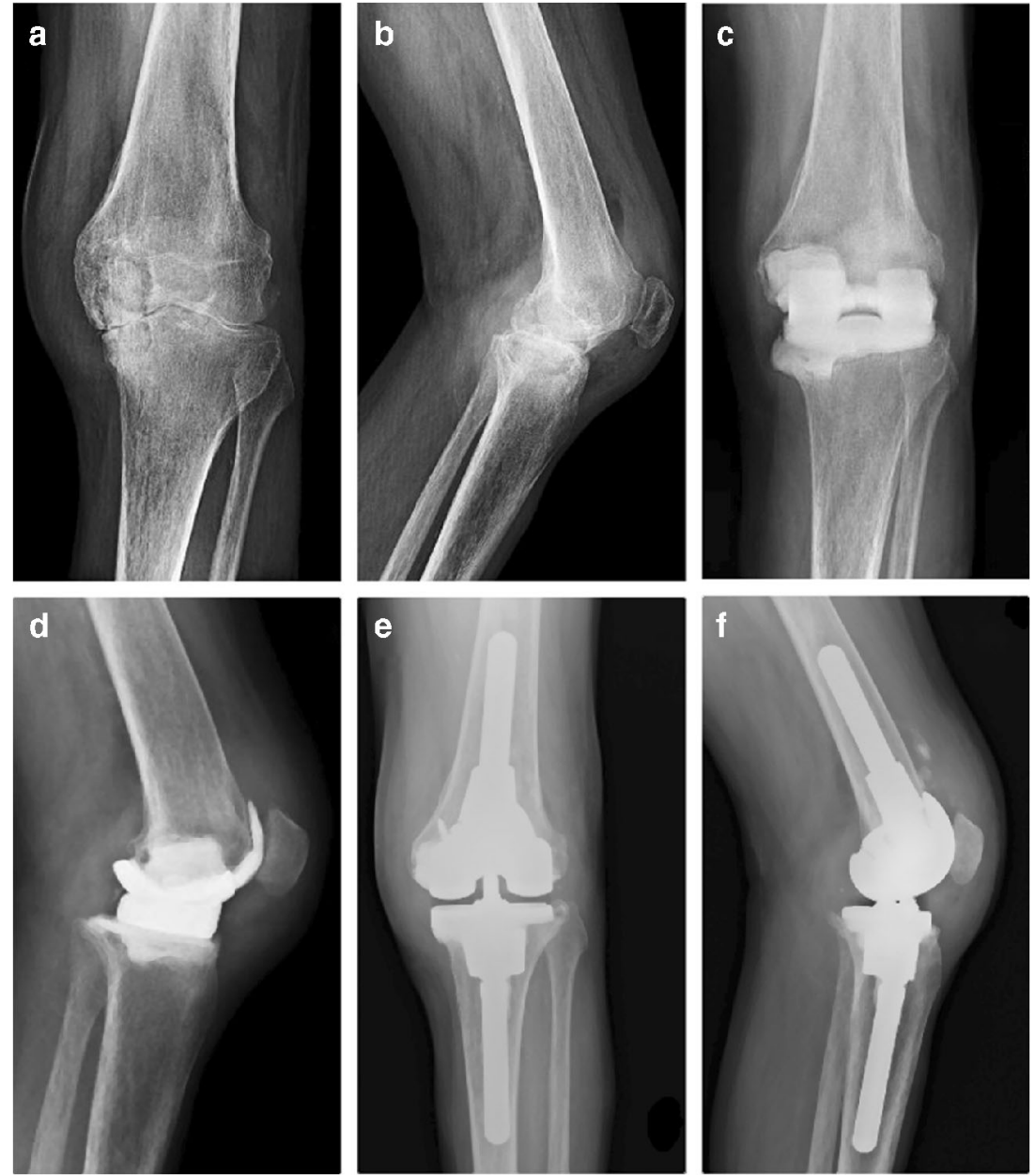

this point of view, a staged approach is safer and more advisable for chronic SA management.

Scores obtained at final follow-up from HHS, KSS, and KSS-F were classified as good to excellent. Two poor results were registered in patients with prior post-surgical sequelae, which affected the final scores, as mentioned in the "Results" section. These results are comparable with those available in the literature.

Different types of spacers have been used in the setting of two-stage surgery; some authors have used prefabricated spacers, while others have used handmade cement spacers or cement beads [10, 26-28]. However, cement spacers seem to guarantee better functional outcomes during the period between stages when compared with cement beads $[9,14,29$, 30]. In 2019, Li et al. [31] conducted a comparative analysis on patients who received two-stage exchange arthroplasty following SA; patients in group I underwent the Girdlestone procedure and subsequent TJR, whereas patients in group II were implanted with a cement spacer at the first stage. The presence of the spacer effectively maintained leg length and simplified the second surgery, decreasing blood loss and operative time. Based on the specific bone defect encountered in the first stage, we used a preformed antibiotic-loaded cement spacer loaded with vancomycin and gentamicin. A handmade acetabular spacer was always coupled to the preformed spacer in the SA of the hips [13]. In knees, reinforced stems were incorporated into the preformed spacer when needed to guarantee more stability. In our cohort of patients, such parameters as LLD and offset did not demonstrate any significant difference from pre- to post-operative values, corroborating the assumption that spacers can efficiently preserve the length and appropriate muscular tension of the treated limb. However, two cases $(4.3 \%)$ of hip spacer dislocation were registered.

Although two-stage arthroplasty is a reliable procedure, surgeons should consider related complications, such as mortality, which is higher compared to that associated with other treatments (e.g., one-stage surgery), and mechanical or septic complications that the patient could undergo during the interstage period [32-34]. In a recent study, Xu et al. [30] found that older age, infection by a resistant pathogen, and high preoperative levels of CRP were independent predictors of treatment failure after two-stage exchange arthroplasty for SA. At the same time, they found that serum ESR, CRP, and interleukin 6 (IL-6) had no benefits in predicting infection 
persistency before second-stage prosthesis implantation. In our series, in four cases $(8.6 \%)$, patients had complications related to the spacer, which were successfully managed with spacer exchange in two (4.3\%) cases and conversion to TJA in the other two $(4.3 \%)$ cases, with optimal final outcomes.

Chronic SA often massively impairs bone stock, especially on the acetabular side (Fig. 3). The subsequent necessary debridement leads to massive bone loss in hips and in knees. The surgeon should be aware of this feature of SA and should always be prepared to manage complex bone defects (Fig. 4). In such surgical situations, an extremely accurate spacer implantation tailored to a patient's bone defects should prevent further bone loss and interstage complications.

It is important to highlight that several limitations affect this study. The retrospective nature of the analysis contains inherent limitations that must be considered when evaluating results. Although we applied our institutional two-stage surgery protocol to all the patients included, the type of spacer and antibiotic therapy were individualized, and this could have resulted in a bias in the analysis. The absence of control groups made any considerations on different treatment options impossible, and the small sample size limits the statistical power of this analysis. Different types of SA (post-infiltrative, post-surgery, primary) were all analyzed together, representing a diagnostic bias of our analysis. Finally, no further investigations (e.g., PET) have been performed during follow-up to exclude late-onset chronic infections and confirm a disease-free condition. However, the strengths of this study were the prospective collection of data and relatively long follow-up ( $>5$ years), as well as that all the patients underwent a standardized protocol of treatment and follow-up and diagnoses and surgery were performed in a standard manner by the same surgeon.

\section{Conclusions}

Two-stage arthroplasty provides good to excellent clinical outcomes in cases of active SA of the hip and the knee, as well as high percentages of infection control and implant survival. During the interstage period, cement spacers maintained adequate biomechanical parameters of the affected limbs. More high-quality case-control studies are needed to clarify which is the best treatment in the setting of SA.

Availability of data and material Complying with field standards.

Author contribution Antonio Russo: methodology, data collection and analysis, original draft writing. Luca Cavagnaro: conceptualization, methodology, original draft writing. Francesco Chiarlone and Antonio Clemente: data collection and material organization. Sergio Romagnoli and Giorgio Burastero: supervision, project administration, review and editing of the original draft.
Funding Open access funding provided by Università degli Studi di Genova within the CRUI-CARE Agreement.

\section{Declarations}

Ethics approval Approved by the local institutional review board.

Consent to participate Patients gave their informed consent to participate this study.

Consent for publication Patients gave their consent to publish clinical data contained in this study.

Conflict of interest The authors declare no competing interests.

Open Access This article is licensed under a Creative Commons Attribution 4.0 International License, which permits use, sharing, adaptation, distribution and reproduction in any medium or format, as long as you give appropriate credit to the original author(s) and the source, provide a link to the Creative Commons licence, and indicate if changes were made. The images or other third party material in this article are included in the article's Creative Commons licence, unless indicated otherwise in a credit line to the material. If material is not included in the article's Creative Commons licence and your intended use is not permitted by statutory regulation or exceeds the permitted use, you will need to obtain permission directly from the copyright holder. To view a copy of this licence, visit http://creativecommons.org/licenses/by/4.0/.

\section{References}

1. Matthews PC, Dean BJ, Medagoda K, Gundle R, Atkins BL, Berendt AR, Byren I (2008) Native hip joint septic arthritis in 20 adults: delayed presentation beyond three weeks predicts need for excision arthroplasty. J Infect 57(3):185-190. https://doi.org/10. 1016/j.jinf.2008.07.001

2. Nair R, Schweizer ML, Singh N (2017) Septic arthritis and prosthetic joint infections in older adults. Infect Dis Clin N Am 31(4): 715-729. https://doi.org/10.1016/j.idc.2017.07.013

3. Stutz G, Kuster MS, Kleinstuck F, Gachter A (2000) Arthroscopic management of septic arthritis: stages of infection and results. Knee Surg Sports Traumatol Arthrosc 8(5):270-274. https://doi.org/10. 1007/s001670000129

4. Charlton WP, Hozack WJ, Teloken MA, Rao R, Bissett GA (2003) Complications associated with reimplantation after girdlestone arthroplasty. Clin Orthop Relat Res 407:119-126. https://doi.org/ 10.1097/00003086-200302000-00019

5. Kantor GS, Osterkamp JA, Dorr LD, Fischer D, Perry J, Conaty JP (1986) Resection arthroplasty following infected total hip replacement arthroplasty. J Arthroplast 1(2):83-89. https://doi.org/10. 1016/s0883-5403(86)80045-6

6. Diwanji SR, Kong IK, Park YH, Cho SG, Song EK, Yoon TR (2008) Two-stage reconstruction of infected hip joints. J Arthroplast 23(5):656-661. https://doi.org/10.1016/j.arth.2007.06. 007

7. Jupiter JB, Karchmer AW, Lowell JD, Harris WH (1981) Total hip arthroplasty in the treatment of adult hips with current or quiescent sepsis. J Bone Joint Surg Am 63(2):194-200

8. Kelm J, Bohrer P, Schmitt E, Anagnostakos K (2009) Treatment of proximal femur infections with antibiotic-loaded cement spacers. Int J Med Sci 6(5):258-264. https://doi.org/10.7150/ijms.6.258 
9. Regis D, Sandri A, Rizzo A, Bartolozzi P (2010) A preformed temporary antibiotic-loaded cement spacer for the treatment of destructive septic hip arthritis: a case report. Int J Infect Dis 14(3): e259-e261. https://doi.org/10.1016/j.ijid.2009.04.019

10. Papanna MC, Chebbout R, Buckley S, Stockley I, Hamer A (2018) Infection and failure rates following total hip arthroplasty for septic arthritis: a case-controlled study. Hip Int 28(1):63-67. https://doi. org/10.5301/hipint.5000538

11. Seo JG, Moon YW, Park SH, Han KY, Kim SM (2014) Primary total knee arthroplasty in infection sequelae about the native knee. J Arthroplast 29(12):2271-2275. https://doi.org/10.1016/j.arth.2014. 01.013

12. Bauer T, Lacoste S, Lhotellier L, Mamoudy P, Lortat-Jacob A, Hardy P (2010) Arthroplasty following a septic arthritis history: a 53 cases series. Orthop Traumatol Surg Res 96(8):840-843. https:// doi.org/10.1016/j.otsr.2010.06.009

13. Burastero G, Basso M, Carrega G, Cavagnaro L, Chiarlone F, Salomone C, Papa G, Felli L (2017) Acetabular spacers in 2-stage hip revision: is it worth it? A single-centre retrospective study. Hip Int 27(2):187-192. https://doi.org/10.5301/hipint.5000446

14. Fleck EE, Spangehl MJ, Rapuri VR, Beauchamp CP (2011) An articulating antibiotic spacer controls infection and improves pain and function in a degenerative septic hip. Clin Orthop Relat Res 469(11):3055-3064. https://doi.org/10.1007/s11999-011-1903-1

15. Nazarian DG, de Jesus D, McGuigan F, Booth RE Jr (2003) A twostage approach to primary knee arthroplasty in the infected arthritic knee. J Arthroplast 18(7 Suppl 1):16-21. https://doi.org/10.1016/ s0883-5403(03)00343-7

16. Harris WH (1969) Traumatic arthritis of the hip after dislocation and acetabular fractures: treatment by mold arthroplasty. An endresult study using a new method of result evaluation. J Bone Joint Surg Am 51(4):737-755

17. Insall JN, Dorr LD, Scott RD, Scott WN (1989) Rationale of the Knee Society clinical rating system. Clin Orthop Relat Res 248:1314

18. Hug KT, Alton TB, Gee AO (2015) Classifications in brief: Brooker classification of heterotopic ossification after total hip arthroplasty. Clin Orthop Relat Res 473(6):2154-2157. https:// doi.org/10.1007/s11999-014-4076-x

19. Ewald FC (1989) The Knee Society total knee arthroplasty roentgenographic evaluation and scoring system. Clin Orthop Relat Res 248:9-12

20. Paprosky WG, Perona PG, Lawrence JM (1994) Acetabular defect classification and surgical reconstruction in revision arthroplasty. A 6-year follow-up evaluation. J Arthroplast 9(1):33-44. https://doi. org/10.1016/0883-5403(94)90135-x

21. Valle CJ, Paprosky WG (2003) Classification and an algorithmic approach to the reconstruction of femoral deficiency in revision total hip arthroplasty. J Bone Joint Surg Am 85-A(Suppl 4):1-6. https://doi.org/10.2106/00004623-200300004-00001

22. Engh GA, Parks NL (1997) The management of bone defects in revision total knee arthroplasty. Instr Course Lect 46:227-236

23. El-Ganzoury I, Eid AS (2015) Two-stage arthroplasty using functional temporary prosthesis to treat infected arthroplasty and septic arthritis of the hip. J Orthop 12(Suppl 1):S86-S93. https://doi.org/ 10.1016/j.jor.2014.04.006
24. Anagnostakos K, Duchow L, Koch K (2016) Two-stage protocol and spacer implantation in the treatment of destructive septic arthritis of the hip joint. Arch Orthop Trauma Surg 136(7):899-906. https://doi.org/10.1007/s00402-016-2455-3

25. Huang TW, Huang KC, Lee PC, Tai CL, Hsieh PH (2010) Encouraging outcomes of staged, uncemented arthroplasty with short-term antibiotic therapy for treatment of recalcitrant septic arthritis of the native hip. J Trauma 68(4):965-969. https://doi.org/ 10.1097/TA.0b013e3181af6e70

26. Romano CL, Romano D, Meani E, Logoluso N, Drago L (2011) Two-stage revision surgery with preformed spacers and cementless implants for septic hip arthritis: a prospective, non-randomized cohort study. BMC Infect Dis 11:129. https://doi.org/10.1186/14712334-11-129

27. Chen CE, Wang JW, Juhn RJ (2008) Total hip arthroplasty for primary septic arthritis of the hip in adults. Int Orthop 32(5):573580. https://doi.org/10.1007/s00264-007-0366-1

28. Kirpalani PA, In Y, Choi NY, Koh HS, Kim JM, Han CW (2005) Two-stage total knee arthroplasty for non-salvageable septic arthritis in diabetes mellitus patients. Acta Orthop Belg 71(3):315-320

29. Shen H, Wang QJ, Zhang XL, Jiang Y (2013) Novel articulating medullary-sparing spacer for the treatment of infectious hip arthritis. Orthopedics 36(4):e404-e408. https://doi.org/10.3928/ 01477447-20130327-13

30. Xu C, Kuo FC, Kheir M, Li X, Chai W, Chen JY (2019) Outcomes and predictors of treatment failure following two-stage total joint arthroplasty with articulating spacers for evolutive septic arthritis. BMC Musculoskelet Disord 20(1):272. https://doi.org/10.1186/ s12891-019-2652-7

31. Li W, Fang X, Zhang C, Xu Y, Huang Z, Yu Z, Zhang W (2019) Comparison of efficacy and complications between two types of staging arthroplasty in treating chronic septic hip arthritis: a retrospective clinical study. Exp Ther Med 17(5):4123-4131. https:// doi.org/10.3892/etm.2019.7430

32. Barton CB, Wang DL, An Q, Brown TS, Callaghan JJ, Otero JE (2020) Two-stage exchange arthroplasty for periprosthetic joint infection following total hip or knee arthroplasty is associated with high attrition rate and mortality. J Arthroplast 35(5):1384-1389. https://doi.org/10.1016/j.arth.2019.12.005

33. Burastero G, Alessio-Mazzola M, Cavagnaro L, Chiarlone F, Carrega G, Capello AG, Lovisolo S, Felli L (2020) Conservative two-stage revision with primary components of infected total hip arthroplasty: an analysis of survival, clinical and radiographic outcomes. PLoS One 15(10):e0239981. https://doi.org/10.1371/ journal.pone.0239981

34. Alessio-Mazzola M, Repetto I, Russo A, Clemente A, Ventura N, Formica M, Burastero G, Felli L (2020) Permanent spacers are a reliable solution for peri-prosthetic shoulder infection: a systematic review. HSS J 16(3):272-279. https://doi.org/10.1007/s11420-02009755-7

Publisher's note Springer Nature remains neutral with regard to jurisdictional claims in published maps and institutional affiliations. 